\title{
Revisiting Tertiary Education System in Bangladesh: In Quest for Unraveling Existing Issues and Challenges
}

\author{
Shah Md. Azimul Ehsan 1,2*) \\ ${ }^{1}$ Global Development Institute, University of Manchester, Oxford Rd, Manchester M13 9PL, \\ United Kingdom. \\ 2Department of Public Administration, Faculty of Social Sciences, Jagannath University, 9-10, \\ Chittaranjan Avenue, Dhaka 1100, Bangladesh.
}

Received: 2021-02-01; Accepted: 2021-02-20; Published: 2021-04-30

\begin{abstract}
Once termed as a basket case, Bangladesh is now a development wonder. Recently, it has entered the cluster of lower-middle-income countries and is predicted to join the cohort of developed ones by 2041. However, the challenge that lies ahead is to sustain the current economic growth with the emerging threat of the fourth industrial revolution (4IR). There is no doubt that the country have the upper hand in order to counter these emerging critical scenario with its huge number of youths. Nonetheless, it will be pertinent to turn these youth force into productive human capital through providing both general and technical education in order to yield higher returns. On this backdrop, this study attempts to know whether our existing tertiary education system is rendering quality education to convert our youth force into effective human resources. Using qualitative tools of social research and drawing information from various secondary sources, the study argues that the existing tertiary education system is failing to produce skilled human resources which is again resulting in lower returns to the economy. Undoubtedly there has been quantitative progress in tertiary level education; nevertheless, the worrying factor has been regarding its quality. The crisis has not happened owing to the absence of adequate policy framework rather the translation of those into reality. This study offers a modest suggestion to take immediate steps by the government of Bangladesh to implement the recommendations as stated in the key policy instruments related to education and skill development along with the significant increase in the budgetary allocation for the tertiary education sector. In addition, efforts has to be put for transforming the existing University Grants Commission (UGC) into Higher Education Commission (HEC). Moreover, activation of the accreditation council is now a crying need for further improving the quality of education at the tertiary level.
\end{abstract}

Keywords: Bangladesh; Education; Employment; Labor Force; Skills; Tertiary

How to Cite: Ehsan, S.M.A. (2021). Revisiting Tertiary Education System in Bangladesh: In Quest for Unraveling Existing Issues and Challenges. Journal of Contemporary Governance and Public Policy, 2(1), 45-66. https://doi.org/10.46507/jcgpp.v2i1.33.

Permalink/DOI: https://doi.org/10.46507/jcgpp.v2i1.33 


\section{Introduction}

Bangladesh, a transitional country of South Asia, was once termed as a 'bottomless basket' by the then US Secretary of the state, Henry Kissinger. However, over the years, the country has done wonders in terms of various socio-economic development indicators compared to its neighboring counterparts (Ahsan, 2019). From successfully cutting down fertility rates, slashing infant mortality rates, and promoting gender equality in availing educational opportunities (both at the primary and secondary levels), the nation has come a long way (Ahsan, 2019). It aims to be a middleincome country by 2021, achieve SDGs by 2030, and enter the group of developed countries by 2041. The country's wealth in achieving these goals lies in its youth of 80 million who are aged between 15 to 35 years. However, it will be pertinent to turn these youth force into productive human capital through providing both general and technical education along with modern, innovative, and creative skills (Mannan, 2015). As a matter of fact, the Government of Bangladesh (GOB) have reacted to the task. They have rightly recognized that there is a continuous need for investment into education and skills development. This is because it will help to boost productivity. Therefore, GOB has made it a priority at the policy level in order to implement those key strategies (T. Rahman et al., 2019).

It is no longer a debate that an aura of positives changes has occurred in Bangladesh's tertiary education. To be more specific, there has been a significant amount of expansion, growth and reach for tertiary education in the last few years (Mannan, 2017). At present, the literacy rate in Bangladesh is 63.08 percent and the rate of higher education receiving students is 16 percent (UNESCO, 2012). The number of university students has increased to 3.9 million in 2019 which was 31,000 and 1.9 million in 1972 and 2009 respectively (Hossain, 2019). As per an estimation of the University Grants Commission (UGC) of Bangladesh, the overall enrollment of students at the tertiary level might reach to 4.6 million by 2026 (Mannan, 2017). In a span of ten years, i.e. from 2009 to 2019, the number of public universities in the country has risen from 31 to 47 . During the same period, there has also been a surge in the number of private universities from 51 to 105 (S. Ahmed, 2019). Despite such rapid growth and quantitative improvement in tertiary education, in recent years, many questions have been raised about its quality and its linkage with employability (Hossain, 2019). According to a recent study conducted by World Bank (2019), Bangladeshi universities have been below par in terms of any international ranking system. This again puts a question mark of the overall quality of education at the tertiary level.

Around 20 million youths enter the job market every year in Bangladesh. However, it is rather irony that bulk of them fail to get placement in their expected fields. This is because they have limited job specific skills and competences which the employers are demanding. It is no doubt that these youths who cannot be absorbed by the job market may turn out to be detrimental for the developmental cause of any country (Reza, 2019). Although the report of the International Labor Organization (ILO) states 29 percent of graduates remain unemployed in Bangladesh, a more recent study by the Bangladesh Institute of Development Studies, BIDS (2019) revealed more shocking 
facts. It states that unemployment rate for the university graduates is currently 38.6 percent (Financial Express, 2019). Interestingly though, when Bangladeshi graduates are struggling to get their desired jobs and many suffering from unemployment, Bangladesh has become a hub for expatriate workers. In other words, around 4, 00, 00 expatriates are working in Bangladesh, that to, with due official process and with all valid documents. In various sectors, these expatriates are found to mostly occupy mid-level executive positions. Consequently, they are siphoning away USD 5 billion annually (Mannan, 2015; 2017). This complex scenario gives a signal that perhaps the existing tertiary education system of Bangladesh is failing to produce skilled graduates. If this situation is to be changed, it is imperative to revisit the entire tertiary education system of the country using a holistic approach for identifying the challenges which it is currently facing. On this backdrop, this paper is an attempt to revisit the overall tertiary education system of Bangladesh for pinpointing the loopholes which have resulted in the production of unskilled graduates. The study also aims to come forward with some pragmatic solutions that will help to solve the existing problem of 'educated unemployment' to a certain extent.

\section{Research Methods}

This paper is highly descriptive and qualitative in nature. Data has been conducted from various secondary sources which include books, book chapters, journal articles, newspaper articles. In addition, relevant policy documents and consultancy reports from development partners, unpublished dissertations related to the research objective were explored following the techniques of content analysis method to substantiate the arguments of this study.

\section{Result and Discussion}

\section{Relationship between education and labor market: Excerpts from existing literature}

Existing literature on education and the labor market can be broadly categorized into two continuums. First group of scholars have raised an optimistic tone regarding the fact that graduates with higher education have a high probability of employment opportunities. While the other group, contesting such claims argue that education necessarily does not ensure the employability of the laborers. Arguments from both the school of thoughts have been discussed here briefly.

Education has a robust relationship with employability (Sharma, 2016). Both classical as well as neo-classical economist, namely William Petty and Adam Smith, and A. Marshall have broadly discussed how the level of education can impact the productivity of labor leading to a net increase in payment (Chen \& Wu, 2007). Later, Schultz (1961) and Becker (1962) strengthened this argument by theorizing the 'human capital theory' (Debbarman, 2019). This notion was further enriched by the study of Schultz (1975) who expounded that education could not only ensure a sustained employment opportunity, but also has the potential to increase employment incomes through enhancing people's "allocation efficiency" in a rather volatile economic conditions (Chen \& $\mathrm{Wu}, 2007)$. Following the prescriptions of Human Capital theory, many countries have put much of their efforts to educational development during 1960s and 1970s (Chen \& Wu, 2007). Various studies, 
for instance, Robinson \& Sexton (1994), Chen and Wu (2007), and Pages \& Stampini (2009) have found out that education has a strong positive influence on employment. These studies also argue that a labor force by dint of education can even create their own employment opportunities through entrepreneurship, and result to selfemployment success. According to Ansell (2005 cited in Tellegen, 2013), education has a considerable role in declining the rate of unemployment. He also expounded that education not only assists adolescents by developing them through acquiring skills and knowledge but also facilitates them to productively participate in the labor market.

However, when too many graduates enter the labor market that can create complexity in ensuring proper employability. The Screening Theory, put forward by Spence (1973), better explains such complexity. According to Screening Theory, educational level of the labor in the markets then plays a signaling role to the employers which reflects what skills they have. Thurow (1975) further solidified this argument through further clarifications by the formulation of the Job-competition Model Theory. More specifically, this theory postulates that although all the applicants hope to get a job placement in their desired positions, organizations usually prefer to employ those who have comparatively high educational qualifications. As a matter of fact, positions at the upper echelons are occupied by the applicants with higher educational qualifications. While those with lower educational levels find themselves being assigned with relatively inferior jobs with less social prestige and recognition. Again, it so happens that the market gets flooded with labor force to such an extent that it exceeds the threshold limit of the demand for required labor force. Therefore, when this sort of rather complex situation happens, the applicants despite having high educational levels fail to get their expected jobs. Consequently, they are forced to look for certain jobs which are rather placed at the lower spectrum that often requires less educational qualifications. However, this have a severe implications on the job prospects for the applicants' with lower educational levels. In other words, such a scenario is created that further squeeze the job market for these applicants with lower educational levels. Ultimately, this leads to a significant rise of unemployment (Boudon, 1974; Hirsch, 1977 cited in Chen \& Wu, 2007). The Job Search Theory also had similar arguments. It states that higher level of education of the applicants open many window of opportunities for them. Put simply, an applicant with high educational level have high prospects of availing an employment opportunity. Conversely, when applicants have low educational level, then they are more exposed to the potential risks of unemployment (European Compassion, 1998 cited in Chen \& $\mathrm{Wu}, 2007)$.

Again, there is another argument as well among scholars. For instance, according to a recent report by UNESCO (2012), education might not always equip adolescents with the skills as the job market requires (Tellegen, 2013). As a matter of fact, it is often observed that many adolescents cannot find work. Even, if they can, such work can barely support them and thus they end up living below the poverty line (UNESCO, 2012). In order to explain this phenomenon, ILO (2013) brought the concept of 'skills mismatch'. In simpler terms, it refers 
to the mismatch between the requirements of the labor market with the skills of the potential employees. According to Thisse and Zenou (2000) and Fasih (2008), this sort of imbalance usually results in unemployment. Most of the jobs in this era of globalization and the fourth industrial revolution require a degree of competence and soft-skills. More specifically, as noted by Fasih (2008 cited in Tellegen, 2013), people who possess cognitive skills, critical thinking ability, problem-solving skills, entrepreneurship, innovation, mindset to work and adapt to changing work environment, etc., and valued by global employers. It is rather ironic that most job seekers, particularly in transitional countries do not possess the above-mentioned competence and soft- skills.

\section{Tertiary Education System in Bangladesh: A Synopsis}

Tertiary education in Bangladesh is provided through four streams. First, through the graduate and the postgraduate programs offered by the universities (public and private); second, through the graduate and postgraduate programs offered by tertiary colleges under the general education system; third, through the diploma programs in the polytechnics under the TVET system; and finally, through theology based education offered by Madrasas(Aliya and Qawmi) (T. Rahman et al., 2019). These different Tertiary education institutes (TEIs) are the main entities which have the responsibility in order to create and disseminate new knowledge. This will be done through a continuous innovation and cuttingedge research by these TEIs. The ultimate aim and objective of these TEIs is the preparation of such a workforce who will have relevant skills and expertise that will be critical in order to meet the demands of the ever changing technology and skill-economy (T. Rahman et al., 2019).

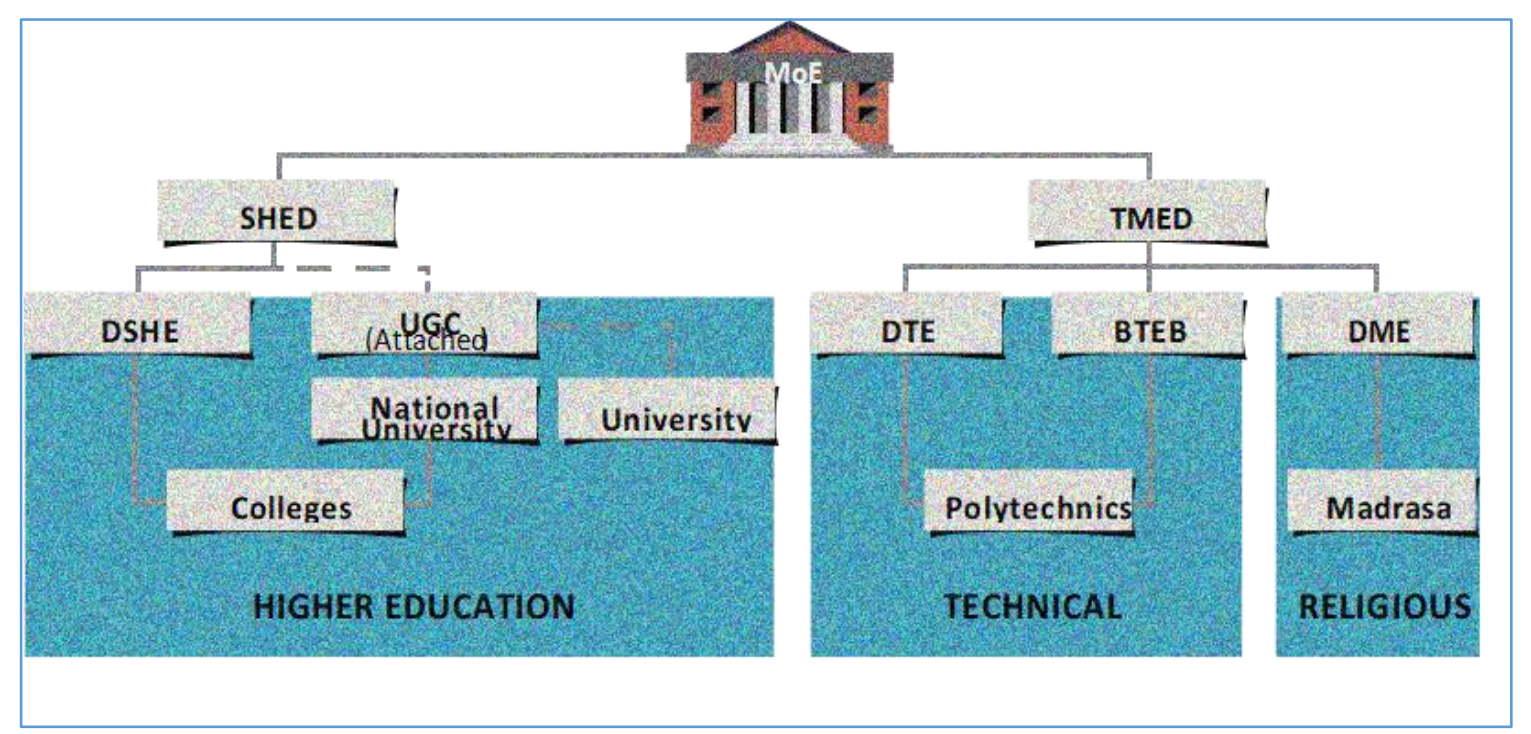

Figure 01: Simplified Organogram for MOE for tertiary Education in Bangladesh $^{1}$

\footnotetext{
${ }^{1}$ Adopted from (Rahman et al.2019, p. 58)

Shah Md. Azimul Ehsan/Revisiting Tertiary Education System in Bangladesh: In Quest for Unraveling Existing Issues and Challenges
} 
According to NEP (2010), the Ministry of Education (MOE) is the apex body, which has the responsibility for giving the policy direction and steering the overall management of the higher education sector in Bangladesh. There are several departments and institutions attached to MOE which function like assisting agencies so that it can implement the governmental policy decisions at the grassroots level. Again, through these agencies, MOE implements various development and non-development programs and projects (T. Rahman et al., 2019). The Secondary and Higher Education Division (SHED) of the MOE (as shown in the figure 01) is responsible for managing the higher education sector through two others bodies., viz.- the Directorate of Secondary and Higher Education [DSHE] and the University Grants Commission ${ }^{2}$ (UGC). The UGC being established in 1972, has the supervision and coordination mandate of both public and private universities. UGC also has the responsibility to maintain the quality standard of university education. Moreover, it is also mandated to manage the allocation of government funding to universities. Furthermore, it provide advice to the government on issues related to tertiary education (T. Rahman et al., 2019). Nonetheless, the public universities enjoy full autonomous status both academically and administratively. They are either governed by their own Acts or by the Presidential Order (T. Rahman et al., 2019). Although private universities enjoy autonomy to a certain extent, they are subject to regulations of the Private

\footnotetext{
${ }^{2}$ According to the President's Order 1973 (No. 10), the role of UGC is the that of a principle agency having the responsibility to coordinate all the matters that falls within the purview of university education pertinent to planning of fund allocation and development. In addition, implementation of higher education and research programs in public universities also fall within their jurisdiction. Moreover, they also have the role of referees in monitoring of public and private universities (Rahman et al. 2019, p.57).
}

University Act 2010 (T. Rahman et al., 2019). When it comes about the tertiary colleges, they do not have any autonomy related to their academic affairs. This is because, most of them (baring a few) are affiliated to the National University ${ }^{3}$ (NU) (as shown in Figure 01), which is one of the largest public universities in Bangladesh. This NU provides the oversighting role of the tertiary colleges $^{4}$ which mostly covers their entire academic affairs. Currently, 72 percent of the total tertiary level students are enrolled with different tertiary colleges under NU (Mannan, 2015). While the administrative affairs (recruitment of teachers and fund allocation) of these tertiary colleges are managed by the Directorate of Secondary and Higher Education (DSHE). However, the governing body (GB), a locally elected entity is generally responsible for steering and facilitating the administrative affairs of the nongovernment colleges (T. Rahman et al., 2019).

Directorate of Secondary and Higher Education (DSHE). However, the governing body (GB), a locally elected entity is generally responsible for steering and facilitating the administrative affairs of the nongovernment colleges (T. Rahman et al., 2019).

\footnotetext{
${ }^{3}$ According to the Act of 1992 (No. 37), the NU has been authorized as the only higher education institution with which all the colleges can be affiliated with. Moreover, the $\mathrm{NU}$ will have the academic responsibility of all these colleges which usually provide post-secondary general education (Rahman et al. 2019, p.58).

${ }^{4}$ The National University has the control in the affiliated colleges in certain affairs like contents of curriculum examinations, student registration, and professional development of teachers. It is important to note here that affiliated colleges neither have the authority to develop their curriculum nor they have any such authority to revise that. Again, there are few tertiary colleges which are affiliated to other public universities rather than NU. In other words, those universities, with which they have been affiliated with have the responsibility to oversee their academic affairs. For instance, in 2017, six government colleges were re-affiliated to University of Dhaka from the NU (Rahman et al. 2019; p. 58).
} 
The Technical and Madrasa Education Division (TMED) of the MOE is responsible for managing the Technical and Vocational Education Training (TVET) sector through the Bangladesh Technical Education Board (BTEB) and the Directorate of Technical Education (DTE) (as shown in figure 01). However, the responsibility of DTE is more of administrative one which include-managing human resources, development activities, and mere academic supervision in the sector ( $\mathrm{T}$. Rahman et al., 2019). While the power and authority for the regulation of the academic activities of this sector falls within the jurisdiction of BTEB. In other words, management of the academic contents, setting standards, and providing certificates to the TVET graduates, all come within the purview of BTEB's responsibilities. As it is the BTEB's onus to design academic programs of polytechnics, on that account, polytechnic institutions have very little autonomy in this regard. There is a total of 23 ministries, including MOE, who are offering various skills training programs targeting different cohorts (T. Rahman et al., 2019). Currently, 14 percent of tertiary level students are enrolled in technical and vocational institutions.

TMED also has a liability for the supervision of tertiary-level religious education (See figure 01). More specifically, Aliya madrasas are supervised by TMED through its Directorate of Madrasa Education (DME) (T. Rahman et al., 2019). However, those tertiary level madrasas have affiliation with the Islamic Arabic University (IAU), for the educational affairs. The graduate and post-graduate degrees which is given by the Aliya madrasa or Islamic Arabic University have the same valuation as degrees given by the Universities. Apart from these madrasas, another huge stream of Madrasa education remains outside the direct grip of the government of Bangladesh. This is popularly known as the Qawmi Madrasa system. Quite interestingly, it has its own management body popularly known as Befaqul Madarisil Arabia, Bangladesh (BMAB). It needs to be mentioned here that $B M A B$ operates independently outside the direct governmental control. For Qawmi madrasas, BMAB is also that entity which has the sole responsibility for the maintenance of the organizational setup starting from the primary level to the postgraduate levels (T. Rahman et al., 2019). Available data suggest the madrasa students, both from Alia and Qawmi stream collectively stand around 8.2 percent of entire tertiary enrolment (Mannan, 2017).

\section{Key Policy Instruments for Tertiary Education}

In order to guide the development priorities and strategies at the tertiary level education in Bangladesh, there are four key government instruments which include (i) Seventh FYP (2016-2020), (ii) National Education Policy (NEP, 2010), (iii) Strategic Plan for Higher Education in Bangladesh (2018-2030), and (iv) National Skills Development Policy (NSDP, 2011). Table 01 succinctly depicts some of the major recommendations stated in these four key policy instruments. 


\section{Table 01: Major recommendations in key policy instruments for tertiary education $^{5}$}

Key Policy

Majors Recommendations

Instruments

\section{National \\ Education \\ Policy (2010)}

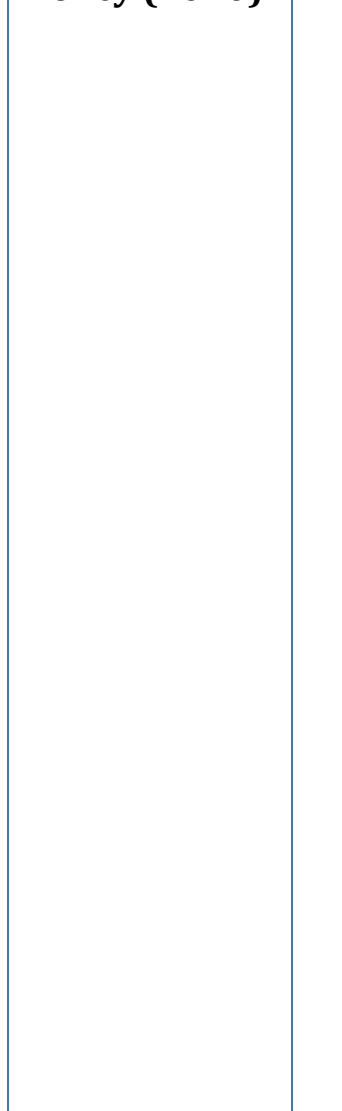

- Advocates for rigorous application of minimum certification standards for TEIs

- Advocates to have such a curricula that will be of international standards at TEIs.

- Advocates the urgency of training/retraining teachers of both universities and colleges for incorporating pedagogical and subject-based knowledge.

- Have enough encouragement for both teachers as well as students of TEIs for taking part in research activities with the intention of finding out the country's specific problems. In order to materialize this, the policy also ensures adequate funding for the capable researchers to undertake original researches fellowship as well as grants for young researchers. Moreover, there is also encouragement for the Universities for promoting institution-based consultancy activities within their peer groups, i.e. their faculty members in order to further strengthen not only their research capabilities and but also their outreach activities.

- Highlights the importance of access to e-resources. For instance, ejournals, e-books through ICT is as a means of sharing and accessing research results.

- There is also encouragement for tertiary-level colleges for engaging in research related activities.

- Strongly advocates for a time to time review and revision of TVET curriculum considering the demand of the job markets at home and abroad

- Emphasizes on filling up vacancies of teachers and

- Advocates for hands on experience on teacher training at industries.

- Advocates for conduction of skills demand survey on a top priority basis. Considering the results of the findings, there is an urgent need for alignment of education and skills qualifications

\begin{tabular}{l|l}
\hline Seventh FYP & Calls to diversity the technical education programs, for instance, ICT
\end{tabular}

(2016-2020)

- Advocates to modernize the skills of training institutions for improving the quality and relevance of education for filling the gap of skills in the labor market

- Advocates to create more and better employment opportunities for youth.

- Has highlighted both teaching and research activities as the predominant roles of the universities.

\begin{tabular}{|c|c|}
\hline $\begin{array}{l}\text { The Strategic } \\
\text { Plan for } \\
\text { Higher } \\
\text { Education } \\
(2018-2030)\end{array}$ & $\begin{array}{l}\text { - Stresses upon the creation of a quality teaching culture at the higher } \\
\text { education institutions } \\
\text { - Advocates for recruitment based on meritocracy, continuous } \\
\text { development of faculty members through training, coaching, mentoring } \\
\text { programs } \\
\text { - Advocates for creation of more relevant academic contents } \\
\text { - Calls for the urgent formation of the national framework for quality }\end{array}$ \\
\hline
\end{tabular}

\footnotetext{
${ }^{5}$ Developed by author by reviewing these policy documents
} 
assurance and accreditation.

- Acknowledges the fact that research and development is an indispensable part of modern economic era both in the government as well as the private sector. On that account, there is an urgency to establish a closer relationship between industry and university. This is because academic research will then be market responsive, i.e. geared to the industrial needs as well as the needs of the country

National Skill - Set flexible, demand driven, and responsive TVET.

Development Policy NSDP (2011)
- Stresses on the upgradation of the competency-based skills qualifications recognition system, i.e. National Technical and Vocational Qualifications Framework (NTVQF).

- Advocates to involve the private sector greatly in order to set the standard and training provisions.

- Highlights the importance of having accurate skills and also emphasizes the role of a labor market information system that helps in planning proper skills and development strategies.
For translating the policy improving the quality of education, the government has prioritized on certain areas like infrastructural development. This mostly include setting up of libraries and laboratories as well as the procurement of scientific equipment's in the educational institutions at the tertiary level. In addition, with the aim of fostering science and research education and making the young generation interested to study science and technology, particularly ICT education, the government has invested significantly in establishing new science and technology universities (T. Rahman et al., 2019). Moreover, UGC has successfully implemented the Higher Education Quality Enhance Project (HEQEP) from 2009-2018 through the funding of the World Bank. Through the HEQEP project, public universities have been brought under the internet facilities coverage. Moreover, the inclusion of modern virtual classrooms (that are connected via the Bangladesh Research and Education Network) in these public universities, is facilitating in establishing visual interactive contact not only amongst themselves but also with any university or research organizations across the globe (Mannan,
2017). Moreover, provisions have been made so that all universities (public and private), have the access to academic ejournals and e-books from world class publishers. This has been possible because of the installation of the university digital library facility (UDL) by UGC. Both the students as well as the faculty members can enjoy this facility (Mannan, 2017; Topader, 2019). In order to further enhance the quality of education at the tertiary level, the government is planning to initiate the 'Higher Education Acceleration and Transformation" (HEAT) project with the financial assistance of the World Bank. Currently, the government has focused on the tertiary level colleges and planning how to formulate a sector development strategy for those entities (T. Rahman et al., 2019).

\section{State of Job market outcome of Tertiary graduates: A Sorry Tale}

The above discussion clarifies the fact that there is enough commitment from the government to promote quality education and skill development in TEIs. Despite such commitment at the policy level by government, higher concerns have been raised regarding the tertiary education system of our country for some valid 
reasons. This is because TEIs have significantly failed to produce skilled graduates. For instance, the report of Bangladesh Labor Force Survey (20162017) states the rate of unemployment for graduates with tertiary educational qualifications was around 11.2 percent. Quite alarmingly, this rate of unemployment was about three times higher than the national mean unemployment rate. More specifically, in 2017, the country's average rate of unemployment was 4.2 percent. Again, Rahman et al (2019) notes that despite completing graduation, more than one third of these cohorts are found to stay jobless or without job placements. Put simply, it usually takes around one or two years on average for the graduates (regardless of the type of graduating institutions) to get a decent job. While few are seen to pursuing further higher education with the intention of gaining more skills and qualifications (Rahman et al, 2019). If the graduates' employment is delayed for obtaining higher educational qualifications, that is quite understandable. However, what makes it more frustrating when the graduates despite having 16-17 years of education (10 years schooling, 2 years higher secondary, and 4-5 years at tertiary level) crowd in coaching centers or other specialized institutes for skill development. It again puts a question mark on the quality of education being rendered at TEIs in particular because these TEIs were supposed to make them well prepared for the market needs.

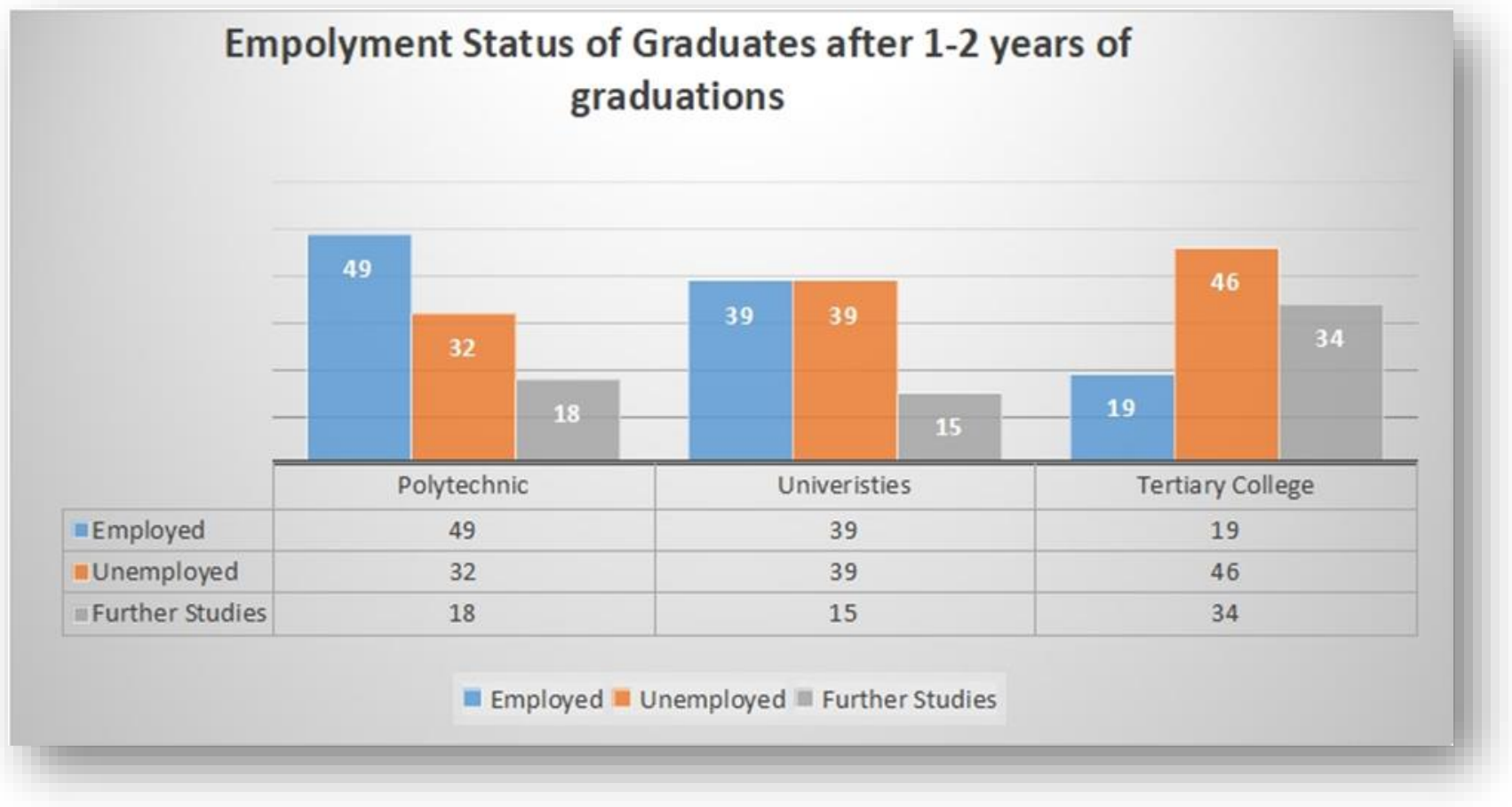

Figure 02: Status of employment for graduates after 1-2 years after graduation ${ }^{6}$

\footnotetext{
${ }^{6}$ Adopted from Graduate Tracer Studies $(2016,2017,2018)$ for employment status cited in (Rahman et al, 2019:19)
} 
However, it seems that this phenomenon of graduate unemployment, with a certain period of joblessness, has become a new norm in Bangladesh. In fact, it has become such an unavoidable reality that most of the graduates in the country have to encounter with. Another interesting phenomenon that has been observed is that there are considerable differences across the type of tertiary level educational institutions, as has been discussed earlier. As a matter of fact, the employment outcomes of these graduates from diverse educational backgrounds also shows significant variation. Nonetheless, the alarming factor is that the graduates from colleges affiliated with NU have appeared to be performing below par. More specifically, only around one fifth on the total number of tertiary college graduates can avail either fulltime or part-time employment opportunities. However, almost fifty percent of the total number of tertiary college graduates remain unemployed (T. Rahman et al., 2019). A study conducted by Ahsan (2019) suggests that around 46 percent of National University graduates require a minimum of 3 years to find a job. Meanwhile, employment outcomes for TVET graduates appear somewhat better. The possible explanation can be that polytechnic graduates are valued more in the job market and have higher chances of availing job opportunities in contrast to the universities or colleges graduates because of their competitive advantage of having necessary skills and relevant technical knowledge (T. Rahman et al., 2019). Figure 02 illustrates these facts more explicitly.

The state of employment outcome for university graduates is also below the satisfactory level. However, according to the findings of BIDS (2019), the rate of employment for the private university graduates is relatively higher compared to the public university graduates. To be more specific, whereas 44 percent private university graduates can get job placements, only 32 percent of their counterparts from public universities can fair off and stay in the hunt by getting employed in various sectors. Moreover, the rate of unemployment is much higher when it comes to Madrasa students, particularly the Qawmi ones. A recent study conducted by Abul Barakat has found that around 75 percent of students of Qawmi madrasa remain jobless for a lack of expertise despite the recent declaration from the government regarding the recognition of a higher certificate of Qawmi madrasa (Dawra-e-hadith) equivalent to a post-graduate degree (Daily Star, 2018).

\section{Issues and Challenges with current tertiary education system: A Critical Analysis}

Thus, the bottom line is that the tertiary education system of Bangladesh is certainly facing challenges to render quality education which is resulting in long spells of unemployment. This again puts two fundamental questions regarding the fact that whether these graduates from TEIs lack job readiness or is it the something associated with dearth of relevant skills. Regarding this, Thisse and Zenou (2000) and ILO (2013) rightly pointed out that when such an imbalance occurs between the skills required by the market compared to the graduates acquired skills, this ultimately leads to unemployment or even underemployment. This situation has not happened in Bangladesh for one linear reason. Rather an aura of factors which are responsible for this situation in 
country have been unpacked and pinpointed below.

\section{Curricula not being updated and aligned to industry needs}

Although NEP (2010) has
made recommendations for
formulating curricula that will be of international standards at tertiary educational institutions, the outcome has been rather disappointing. To say the least, neither the curricula nor the academic courses at the tertiary level have been updated at regular intervals. Of course there have been exception in certain universities or departments, but this have been the common scenario throughout the country. Again, there is barely any research concentrated on the students' academic (S. Momin, 2019). Reza (2019) rightly noted that most often, curricula are found mainly focused on theoretical knowledge with little emphasis on how to link the theoretical knowhow into practice.

Again, the content of the curriculum is not in congruence with the industry needs particularly the RMG sector. Currently, only two universities, namely BGMEA University of Fashion and Technology (BUFT) and Bangladesh University of Textiles (BUTEX), are there in the country that have specific focus on the garments and textile industry. There are some degrees like textile and industrial engineering which are being offered by some universities. Graduates from these subjects also can have high prospects in fulfilling the demand of the RMG sector (S. Rahman, 2019). However, what is quite shocking is that, despite having more than a hundred private universities in the country, very few of them offer courses on industrial engineering. Moreover, modules related to labor management, managing industrial relations, managing occupational health, and safety issues are not offered by most universities. Even, the most leading and frontline private universities also do not have a specific center on Corporate Social Responsibility (CSR). Furthermore, the existing curriculum also lacks some vital elements like how to groom students in becoming smart merchandisers for negotiating with buyers (S. Rahman, 2019).

The case is more severe for NU where the curriculum is rather outdated, which have very little relevance in addressing the emerging challenges of this era of fourth industrial revolution. For instance, the BA in English curriculum has been designed in such a way that it is not incumbent on the students to take speaking and listening modules. Consequently, most of students who do complete their graduation in English end up with mere paper qualifications having limited communicating skills in English. Ahmed (2019) noted that although many tertiary colleges have separate departments for offering science related courses like Chemistry, Physics, Zoology, Botany, etc., however, the ground reality is that they are not well placed in terms of logistic support or infrastructural set up. More specifically, baring a few, most of these colleges do not have adequate laboratory facilities. This limits the students' chances to gain the practical knowledge which again can have severe implications after their graduation. Having no alternative, these students follow the pathways and trends of their predecessors. In other words, they complete their graduation by memorizing answers of certain number number of questions and crowd the job market without in depth knowledge or hands-on skills (Ahmed, 2019). The curriculum being 
followed by madrasa (both Aliya and Qawmi) are also outdated and not market sensitive.

\section{Traditional methodology}

Teaching

There is no denying the fact that there has been a great amount of concern for more than a decade about how to design and shape the academic curriculum and put it in the same wavelength of the industry needs. Moreover, the task do not end there rather to yield positive results, perhaps, more challenging task is how to deliver that in the classroom and create such a mindset that would emphasize on the application of learning, i.e. how to relate the theoretical knowledge with real world problems and bring solutions. Despite having such concerns, the education system which TEIs are following is pretty much outdated and rigid. There exists only one way of interaction between student and teacher (Rahman et al., 2019). Teaching at these institutions primarily involves rote-learning, which induces the passivity of students and does not promote or encourage critical thinking and softskills - all of which are essential skills in the modern job market. (T. Rahman et al., 2019). Quite astonishingly, still, lecturing method is mostly being used in TEIs. Undoubtedly, this is a problematic because there has been a paradigmatic shift in the teaching arena. More specifically, the current paradigm of pedagogy encourages education based on 'learner centric' approach and welcomes the active engagement and participation of the students in the learning process. This is quite contrasting to the traditional paradigm that narrowly focused on teacher centric approach that has rather ignored the active engagement of students in the active learning process, since time immemorial (Topader, 2019). Moreover, the classroom facilities in TEIs throughout the country portraits a picture of many students sitting in several rows of benches, having very limited spaces that hardly leave any scope for adopting critical thinking, group discussion, problem-solving, simulations, role-playing, case analysis, and other student interactive techniques. Again, the absence of essential multimedia equipment such as projectors and speakers prevent lecturers from effectively communicating in large classrooms. Albeit leading private universities have adopted these into their curriculum, the story remains the same for the bulk of the TEIs across the country (Ahsan, 2019).

\section{Lack of continuous supply of qualified teachers}

Continuous supply of qualified teachers is another major concern of ensuring quality education at TEIs. The concern is applicable to both public as well as private universities. TIB (2019) noted a few irregularities in the recruitment of teachers in public universities. Mushrooming of private universities has also attracted many to take up teaching as a profession who perhaps have never aspired to be teachers. Not everyone can be teachers and especially when it comes to teaching at universities, then definitely there is a need for those faculties who have the proper qualification and passion to serve academia. Regarding this problem of intrusion of many free-riders in private universities as teachers, Andaleeb (2019) commented critically that they were at those positions either not finding proper jobs or they were looking for something on an ad-hoc basis to support them. Moreover, as the private universities are largely 
unregulated, doubts are often cast over the transparency of the teacher recruitment process.

There is a dearth of qualified teachers in the tertiary colleges affiliated with the National University. This is because of the generalized recruitment system through which they join the service. In other words, teachers teaching in government colleges affiliated with National University get their appointments through the Bangladesh Civil Service (BCS) examination under the Education Cadre. The assessment process for recruitment is done through preliminary examination, where multiple choice questions are mostly set on diverse subjects, which often does not require to be specialized on any relevant field. Rather candidates can pass out the first huddle through memorizing. Secondly, they have to sit for written examinations on specific disciplines where again, candidates can make their way out through show-casing their memorizing skills in the papers (S. Ahmed, 2019). Again, previous examinations grade have little effect on the selection process much unlike state-run universities. In other words, the conditions are so set where a candidate with an average result (for instance second class) can apply for the post. This implies that a graduate with a mediocre degree can end up being a teacher at NU, and that to for teaching the Masters level students! Moreover, Ahmed (2019) observes that the candidates even do not need to go through an interview or demonstration phase, (as it is done for both public and private universities), where the experts of their respective disciplines will assess his/her subject related knowledge and see whether he/she is the best fit to appointed as teacher to teach at tertiary (S. Ahmed, 2019). Another issue particularly pronounced in district towns is the high number of vacancies in tertiary colleges. Ahsan (2019) rightly noted that the centralized teacher recruitment system ultimately led to time lags sometimes up to 2 years. The selection is further crippled as pointed by Momin (2019) by high rates of turnover within this time period.

\section{Dearth of proper training facility for the faculty members of the Universities}

According to Islam (2016), lower returns from the tertiary level education system is because of the dearth in professionalism and skills of the teachers It is rather ironic that Bangladesh is such a country where a fresh university graduate, who does not have any earlier experience or training of teaching, can instantly be appointed as a lecturer and be asked to go to classroom for delivering lectures. The key assumption that lies here is that a student who has performed really well in various academic parameters by dint of merit will also be a good teacher. However, such generalizations might even backfire. The reality is that in order to prepare someone to be a good teacher, he/she will have to go through several trainings in order to get equipped with necessary skills. However, sadly there is still no scope for providing formal training to university teachers despite the commitments being laid down in NEP (2010) and Strategic Plan for Higher Education (2018-2030) about continuous faculty development through training on both subjectbased knowledge and pedagogical skills. The situation is somewhat better at the college level (Mannan, 2017). Another strange perception that prevails in the Bangladesh academia is that obtaining a Ph.D. 
degree in their respective disciplines will lead to highest form of professional development of the faculty members. After that, very little importance is given to further train university teachers regarding pedagogical skills. In simpler terms, too much emphasis has been put for discipline-specific knowledge development in contrast to other aspects of teaching and learning strategies (Islam, 2016).

\section{Poor funding allocation for tertiary education}

The significance of research in any field, be it science, social sciences, applied sciences, environmental sciences, pharmaceutical sector, etc. can't be overemphasized. Both NEP (2010) and Seventh FYP have enough encouragement for the teachers and the students of tertiary education institutions (both universities and tertiary level colleges) to take part in research activities. In order to materialize that, there is further assurance of adequate research funding for researchers so that they can conduct original and empirical researches (T. Rahman et al., 2019). However, such encouragement is not reflected in terms of budgetary allocation for higher education. The current allocation for education in GDP is less than 2 percent. Quite alarmingly, only 2 percent of that 2 percent is invested for higher education. It is the lowest among all of South Asian countries! (Mannan, 2017) Let's not forget about the system loss, a common phenomenon not only in Bangladesh but also in most of the transitional countries. So if that is taken into consideration, the actual figure of investment for this purpose perhaps will be even lower! Therefore, with this scanty allocation, expecting to do wonders in tertiary education in terms of improving research opportunities and promoting technical and vocational education is rather a day-dream! (Mannan, 2017). It is a general phenomenon in all the developed economies of the world that students get involved in research activities as soon as they get their admission into the universities, i.e. from the undergraduate level. Nevertheless, in context to Bangladesh, Momin (2019) notes that many students can even complete their post-graduation programs that to without having to do any proper research work in any particular area of their subject. This mostly happens because of the lack of research allocations. Lower budgetary allocation along with the absence of loan schemes for tertiary level education also hampers the progress of many potential candidates in getting enrolled in public or private universities. Exceptionally higher tuition fees of private universities which is beyond the reach of the middle class and lower middle-class families make the situation even worse. Thus, the majority of the students (72 percent of the total tertiary level students) get themselves enrolled in tertiary level colleges under NU that has often been criticized for having substandard curriculum, low teaching quality, and inadequate infrastructural support (Momin, 2019; Topader, 2019).

\section{Lower participation in STEM field education}

We are living in an era of the fourth industrial revolution, artificial intelligence which demands more graduates from the field of science, technology, education, and mathematic (STEM) field of education. However, the reality is that only 21 percent of all enrollments at the tertiary level of Bangladesh are in STEM fields whereas it is 40 percent in India and 28 percent in Sri Lanka (T. Rahman et al., 2019). Again, when 
it comes about the tertiary college enrollments in STEM fields, it stands only 9 percent. A survey conducted by World Bank revealed that as the costs associated with providing STEM education are relatively on the higher side, therefore, colleges prefer to offer more generalized courses in humanities and business (T. Rahman et al., 2019).

\section{Absence of a strong quality assurance mechanism}

As mentioned in the earlier part of the paper, UGC has the responsibility to supervise and coordinate public and private universities along with the maintenance of the standard of quality education in the universities. But, it is rather a pity that it still operates with a mandate that is 48 years old, i.e. of 1973. Moreover, despite being a statutory body, it operates with very circumscribed autonomy, in contrast to similar statutory bodies across the globe (Mannan, 2017). When the mandate of 1973 was formulated, there were only four public universities and no private universities which now stands to 47 public universities and 105 private universities respectively. This begs a question about the relevance of that 1973 mandate in the current context when UGC's supervisory role has increased immensely. Albeit prescriptions have been made since 2008 to transform UGC into a Higher education Commission, it has yet not been materialized. Such a petty state of UGC with the obsolete mandate and so much to do seriously hampers the strong quality assurance mechanism.

Several allegations are there against universities (both public and private) in particular which include the shortage of quality teachers, operation of private universities in rented buildings using court stay orders, not complying with Private University Act 2010, etc. (Rashid, 2018). In order to grade the quality of education at the tertiary level, the parliament of Bangladesh have passed a legislation in 2017 for creating an accreditation council that will be an independent body and operate with more autonomy. Despite the fact that the first Chairman of the council was appointed three years ago, i.e. in August 2018, it is rather ironic that the council has yet not been operational (Daily Star, 2018).

\section{Pathways for improving the quality of tertiary education system in Bangladesh}

The critical factor on which the development of a modern society depends to a great extent is the nature and the quality of the tertiary education system. This is because if the tertiary level education is effective, it can significantly contribute to promoting prosperity in the developing economies (Topader, 2019). It is quality higher education that has the potential to prepare people for the economy that will be knowledge based. Moreover, quality higher education also has the merit to provide an impetus for innovation and creativity (S. Momin, 2019). Unfortunately for Bangladesh, the entire tertiary education system had witnessed a long period of stagnation in terms of quality, despite an impressive performance in terms of quantity. Various streams of the tertiary education system have not helped the cause either. End result has been low returns from tertiary education which hovers around 20 percent (T. Rahman et al., 2019). Most countries that are looking to make remarkable economic strides have acknowledged the fact that the key to inclusive growth is education. More specifically, they have emphasized more on quality higher education as a 
means to reach their destination (S. M. Momin, 2016). As Bangladesh is also pursuing the same pathways as other countries, so it is imperative that the current issues and challenges of the tertiary education system, which has been haunting it for quite some time, are adequately addressed. It needs to be mentioned here that corrective measures will yield superior returns in the economy. Based on the discussion made in the previous section, this study offers few mitigating strategies for the concerned policymakers.

First, updating curricula should be given a topmost priority for all TEIs (universities, NU affiliated colleges, and Madrasas) which should be aligned to the industry through the introduction of more practical courses replacing the existing theoretical ones which have little relevance to present context. For making the students sellable in the market in the context of the fourth industrial revolution, the curricula must have a special focus on improving the cognitive skills, communication ability, IT literacy along with the options of internships and field visits.

Second, updating curricula and introducing market needed courses won't heal the problem if qualified, well-trained teachers are not ensured. In order to make that happen, special attention should be given to recruiting teachers in TEIs that will be free of the spoil system. Private Universities also need to follow strict policies in case of hiring faculty members. Even, in the case of tertiary colleges, the government needs to revise the existing recruitment and selection policy where the merit of the candidate is very much less valued.

Third, having an updated curriculum and good teachers in TEIs without proper training can be self- defeating. Thus, this huge number of teachers need to be properly trained up through regular training programs to infuse modern pedagogical ideas. Currently, there is no training institute for university teachers. So immediate steps should be taken for establishing a training institution like BPATC (Bangladesh Public Administration Training Centre), BCSAA (Bangladesh Civil Service Administration Academy). If civil servants and other government officials can be sent on foreign trainings for capacity building, why can't university teachers not be sent? The government should take this policy prescription of foreign training of teachers seriously into consideration as the returns of such programs would be incredibly higher.

Fourth, after updating the curriculum and having qualified teachers, if the TEIs stick to the traditional way of teaching, it will again not serve the purpose. The existing classrooms should be modernized with digital amenities so that teachers can adapt the learnercentric way of teaching. As a result, this will help the students in developing not only their critical thinking potentials but also the problem-solving ability. Again, the learner-centric way of teaching will only be fruitful if the teacher-student ratio can be reduced as has been mentioned in NEP (2010).

Fifth, implementation of all these suggestions for ensuring quality education at TEIs will require a huge investment that current budgetary allocation would simply not allow. Hence, the government must radically raise the allocation for education. Once the budgetary allocation is increased, the government might also think about providing loans to prospective students who can't get enrolled in STEM-based education owing to a limited funding 
opportunities. Moreover, the government should also have a stringent eye so that public funds are properly utilized because there have been reports about certain misappropriation about much talked 'HEQEP' project in the name of socalled infrastructural development (New Age, 2019).

Sixth, Higher education commission (HEC) and independent accreditation council is now a crying need for ensuring the overall assurance and removing the irregularities in both the public and the private universities. The government also needs to regulate the theology-based Qawmi madrasa in particular through certain mechanisms. It is surprising that most of the recommendations of this study can also be found at the policy level commitment of government but sadly a little of those have seen light.

Last, but not the least, all these efforts put for reforming or modernizing the tertiary level education will have very little impact, provided a overhauling and exhaustive changes are not brought into the subsequent lower level of the education pyramid (i.e. primary, secondary and higher secondary levels.). On that account, if the tertiary level education has to match the global standards, echoing on the same tone with Topader (2019), this study recommends that the country's entire education system should be viewed from a holistic perspective. In other words, historical evidences suggest that mere ad hoc, piecemeal and sporadic solutions won't be adequate enough for fixing the existing issues and challenges of this sector.

\section{Conclusion}

From the above discussion, it is evident that although there has been a considerable quantitative improvement in the tertiary education system in Bangladesh, however, there are still questions regarding to what extent its quality has enhanced. If the education system is viewed from an industry perspective, then it suffices to say that it is failing to produce the adequate number of skilled graduates as per the market demand. In other words, the contribution of the education industry to alleviating unemployment or underemployment issues have been below par. This study has unbundled several underlying factors that have plagued the overall tertiary education system in Bangladesh. Nevertheless, it does not mean that these issues cannot be fixed. Rather, through a strong political will and adopting a holistic approach, the current scenario which portraits a picture of gloomy winter can be gradually turned into a sunny summer one. It is expected that the mitigating measures that this study has come up with if taken into consideration and implemented accordingly by the concerned policymakers, will help to change the existing situation to a certain extent. Having said that, it also has to be mentioned here that it would be rather naïve to expect a thorough change overnight. Reaping benefits from the implemented measures will take some time as it is herculean task. However, Bangladeshi policy makers should put it at the top of the priority list in the policy agenda. This is because the nation have certain goals to achieve, for instance vision 2021, Agenda 2030 and Vision 2041. The role of skilled youths and manpower in the achievement of those goals cannot be overemphasized. Hence, it is imperative that Bangladeshi policy makers take a proactive step for enhancing the overall quality of education system at the tertiary level. 
Nonetheless, this study is constrained because of its overreliance on the data from various secondary sources. Despite that, this macro study has portrayed the bigger picture of the story. Nevertheless, there is enough scope for digging more into this topic through empirical shreds of evidence. In fact, further micro studies can be conducted by taking each stream of the tertiary education system (for instance public universities, private universities, colleges affiliated NU, Madrasa, TVET) as a unit of analysis for investigation.

\section{Acknowledgements}

The earlier version of the paper was presented in $7^{\text {th }}$ International Conference of Public Administration and Governance at BPATC, Savar, Dhaka, Bangladesh. The author would like to express his gratitude to the panelists who have provided constructive comments and feedbacks that have helped to sharpen the arguments of this paper.

\section{References}

Ahmed, H. (2019a). Enhancing quality of education. Received from The Financial Express website: https://thefinancialexpress.co $\mathrm{m} . \mathrm{bd} /$ views/columns/enhanci ng-quality-of-education1573654753

Ahmed, S. (2019). Higher education and its purpose for Bangladesh. Received from The Independent website: http://www.theindependentb d.com/printversion/details/1 97907

Ahsan, S. (2019). Tertiary Education in Bangladesh: A Sector in Need of Reform. Received from Data BD website: https://databd.co/stories/tert iary-education-in-bangladesha-sector-in-need-of-reform5290
Andaleeb, S. S. (2019). Future readiness of Bangladesh's higher Educational Institutions. Received from The Daily Star website: https://www.thedailystar.net/ opinion/education/news/futu re-readiness-bangladeshshigher-education-institutions1702786

Ansell, N. (2005). Children, Youth and Development (Taylor \& F). USA: Routledge.

BIDS. (2019). Tracer Study of Graduates of Universities in Bangladesh. Received from https://thinkasia.org/handle/11540/9678

Boudon, R. (1974). Education, Opportunity and Social Inequality. New York: John \& Wiley and Sons.

Chen, Z., \& Wu, Y. (2007). The relationship between education and employment: A theoretical analysis and empirical test. Frontiers of Economics in China, 2(2), 187211.

Daily Star. (2018). Three of four madrasa students remain jobless. Received from The Daily Star website: https://www.thedailystar.net/ city/every-3-four-madrasastudents-remain-jobless1526140

Debbarman, S. (2019). An analysis of labor market integration of visible minorities in Canada: the case of South Asians. University of Manitoba.

Fasih, T. (2008). Linking Education Policy to Labor Market Outcomes. Washington: The World Bank.

Financial Express. (2019). Highly qualified but unemployed! Received from The Financial Express website: https://thefinancialexpress.co 
m.bd/editorial/highly-

qualified-but-unemployed-

1575907815

Government of Bangladesh. (2010). National Education Policy 2010. Received from https://reliefweb.int/sites/reli efweb.int/files/resources/02.

National-Education-Policy2010-English.pdf

Government of Bangladesh. (2011). National Skill Development Policy 2011. Received from International Labour Organization website: https://www.ilo.org/wcmsp5/ groups/public/@asia/@ro-

bangkok/@ilo-

dhaka/documents/publication /wcms_113958.pdf

Government of Bangladesh. (2015). 7th Five Year Plan (SFYP) 2016-2020 Accelerating Growth, Empowering Citizen.

Government of Bangladesh. (2018). Strategic Plan for Higher Education in Bangladesh: 2018-2030. Received from University Grants Commission of Bangladesh website: http://www.ugc.gov.bd/site/p ublications/6dc675fc-db6642bd-88e3-

5 fcbb3a5c497/Strategic-Planfor-Higher-Education-in-bd2018-2030

Hirsch, F. (1977). Social Limits to Growth. London: Routledge and Kegan Paul.

Hossain, M. (2019). Quality of Higher Education and University Ranking. Received from Daily Sun website: https://www.dailysun.com/ar cprint/details/419873/Qualit y-of-Higher-Education-andUniversity-Ranking/2019-0901

ILO. (2013). Global Employment Trends 2013. In Recovering from a second jobs dip. Genève:
International

Labor Organization.

Islam, M. (2016). Future of higher education in Bangladesh. Received from The Daily Star website: https://www.thedailystar.net/ supplements/25thanniversary-special-part3/future-higher-educationbangladesh-211417

Mannan, A. (2015). Tertiary level education in Bangladesh needs relaunching. Received from Daily Sun website: https://www.dailysun.com/ar cprint/details/83808/Tertiary -level-education-inBangladesh-needsrelaunching/2015-10-17

Mannan, A. (2017). Achieving our higher education targets. Received from The Daily Star website:

https://www.thedailystar.net/ educationemployment/achieving-ourhigher-education-targets1366513

Momin, S. (2019). Employability and education. Received from The Independent website: http://www.theindependentb d.com/magazine/details/1937 85/Employability-andeducation

Momin, S. M. (2016). Ensuring quality in higher education. Received from The Independent website:

http://www.theindependentb d.com/post/54276

New Age. (2019). Tertiary education purpose lost in HEQEP project. Received from New Age website: http://www.newagebd.net/art icle/61029/tertiaryeducation-purpose-lost-inheqep-project 
Pagés, C., \& Stampini, M. (2009). No education, no good jobs? Evidence on the relationship between education and labor market segmentation. Journal of Comparative Economics, 37(3), 387-401.

Rahman, S. (2019). Are educational institutions failing the RMG industry. Received from The Daily Star website: https://www.thedailystar.net/ opinion/news/are-

educational-institutions-

failing-the-rmg-industry1829314

Rahman, T., Nakata, S., Nagashima, Y., Rahman, M., Sharma, U., \& Rahman, M. (2019). Bangladesh Tertiary Education Sector Review: Skills and Innovation for Growth. Received from World Bank website:

http://documents.worldbank. org/curated/en/3039615537

47212653/Bangladesh-

Tertiary-Education-Sector-

Review-Skills-and-Innovationfor-Growth

Rashid, H. (2018). Varsity accreditation council in a month. Received from The Independent website: http://www.theindependentb d.com/post/151030

Reza, S. (2019). Bangladesh education systems and employment markets: Challenges and way out. Received from The New Nation website: http://thedailynewnation.com /news/233216/bangladesheducation-systems-andemployment-markets-challenges-and-way-out.html

Robinson, P. B., \& Sexton, E. A. (1994). The effect of education and experience on selfemployment success. Journal of business Venturing, 9(2), 141-156.

S, B. G. (1962). Investment in human capital: A theoretical analysis. Journal of Political Economy, 70(5), 9-49.

Schultz, T. W. (1961). Investment in human capital. American Economic Review, 51, 1-17.

Schultz, T. W. (1975). The value of the ability to deal with disequilibrium. Journal of Economic Literature, 13(3), 836-868.

Sharma, S. (2016). Relation between education and employment outcomes in the Indian labor market: A critical review of the literature. International Journal of Research in Economics and Social Sciences, 6(4), 43-55.

Spence, A. M. (1973). Job market signaling. Quarterly Journal of Economics, 88, 355-374.

Tellegen, B. G. (2013). The Relationship between Education and Labor Market in the Current Context of SubSaharan Africa. Utrecht University.

Thisse, J., \& Zenou, Y. (2000). Skill mismatch and unemployment. Economics Letters, 69(3), 415420.

Thurow, L. C. (1975). Generating Inequality. New York: Basic Books.

Topader, R. (2019). Challenges of quality higher education. Received from The Independent website: http://www.theindependentb d.com/printversion/details/1 90190

UNESCO. (2012). EFA Global Monitoring Report: Youth and Skills. In Putting Education to Work. France: UNESCO. 
(C) 2021 by the Authors. Submitted for possible open access publication under the terms and conditions of the Creative Commons Attribution (CC BY SA) license (https://creativecommons.org/licenses/by-sa/3.0/). 